\title{
KOPI SAJANG MENUJU DUNIA MELALUI PROMOSI DAN PEMBAHARUAN KEMASAN PRODUK
}

M. Sarjan ${ }^{1 *}$, Baiq Jannatun Na'im², Rosita wati ${ }^{3}$, Lalu Zulkifli4, Fuziati ${ }^{5}$, Muhsamar Irawan ${ }^{6}$, Harnawati $^{7}$, Andry Saputra Saptaji ${ }^{8}$, Yahya Himni ${ }^{9}$, Fannindia Nur Pratami ${ }^{10}$, Zul Afrianto ${ }^{11}$

1Dosen Pertanian, Fakultas Pertanian, Universitas Mataram

2, 3Pendidikan Kimia, Fakultas Matematika dan IImu Pengetahuan Alam, Universitas Mataram

${ }^{4}$ Pendidikan Fisika, Fakultas Keguruan Dan Ilmu Pendidikan, Universitas Mataram

${ }^{5}$ Pendidika Pancasila dan Kewarganegaraan, Fakultas Keguruan dan IImu Pendidikan, Universitas Mataram

${ }^{6}$ Pendidika IImu dan Teknologi Pangan, Fakultas Teknologi Pangan dan Agroindustri, Universitas Mataram

${ }^{7}$ Pendidikan Agroekoteknologi, Fakultas Pertanian, Universitas Mataram

${ }^{8}$ Pendidikan IImu Hukum, Fakultas Hukum, Universitas Mataram

${ }^{9}$ Pendidikan Peternakan, Fakultas Peternkan, Universitas Mataram

${ }^{10}$ Pendidikan Akuntansi, Fakultas Ekonomi dan Bisnis, Universitas Mataram

${ }^{11}$ Pendidikan Teknik Elektro, Fakultas Teknik, Universitas Mataram

${ }^{*}$ Co-Author : msarjan@unram.ac.id

\begin{abstract}
ABSTRAK. Desa Sajang kecamatan Sembalun kabupaten Lombok Timur merupakan salah satu desa yang terletak di sebelah utara lereng gunung Rinjani. Desa ini memilki komuditas kopi yang sangat baik. Namun, ada beberapa masalah yang dihadapi oleh produsen kopi di desa ini, salah satunya adalah masalah pemasaran. Lokasi desa yang jauh dari kota membuat pemasaran kopi sajang ini terkendala. Permasalahan ini dapat diatasi dengan membuat alat promosi. Alat promosi disini dapat berupa pamplet, media sosial dan lain sebagainya. Pembuatan media sosial kopi sajang ini bertujuan untuk memudahkan dalam promosi dan kopi tersebut bisa dikenal lebih luas. Metode yang digunakan adalah persiapan program, pembaharuan kemasan produk kopi sajang dan pembuatan media sosial berupa instagram. Hasil dari kegiatan ini adalah kopi sajang dapat dikenal lebih luas dan memudahkan dalam pemasaran dan lebih menarik dari segi kemasan.
\end{abstract}

Kata Kunci: Sajang, kopi, branding, promosi

ABSTRACT. Sembalun affections village subdistrict East Lombok district is a village located on the north slope of Mount Rinjani. The village has an excellent coffee commodity. However, there are some problems faced by coffee producers in this village, one of which is a matter of marketing. Village location away from the city made the affections of coffee marketing is constrained. This problem can be overcome by making a promotional tool. A promotional tool here can be a pamphlet, social media and so forth. Making the affections coffee social media aims to facilitate the promotion and the coffee can be known more widely. The method used is the preparation of the program, the renewal of affections coffee product packaging and manufacturing of social media such as instagram..

Keyword: Sajang, coffee, branding, promotion 


\section{PENDAHULUAN}

Kopi merupakan salah satu minuman yang sangat di gemari oleh masyarakat Indonesia karena rasa dan aromanya. Minuman ini di gemari oleh segala umur secara turun temurun. Kopi merupakan sejenis minuman yang berasal dari proses pengolahan biji tanaman kopi. Kopi digolongkan ke dalam famili Rubiaceae dengan genus Coffea. Secara umum kopi hanya memiliki dua spesies yaitu Coffea arabica dan Coffea robusta (Saputra E., 2008). Minuman ini dapat digolongkan sebagai minuman psikostimulant yang akan menyebabkan orang tetap terjaga, mengurangi kelelahan, dan memberikan efek fisiologis berupa peningkatan energi (Bhara M., 2005). Pada umumnya biji kopi banyak mengandung kafein. Kefein merupakan alkaloid dengan rumus senyawa kimia $\mathrm{C} 8 \mathrm{H} 10 \mathrm{~N} 4 \mathrm{O} 2$, dan rumus bangun 1,3,7- trimethylxanthine (Saputra E., 2008).

Kafein berbentuk kristal panjang, berwarna putih seperti sutra dan memiliki rasa pahit (Ridwansyah, 2002). Menurut Bhara M.(2005) kafein berfungsi sebagai unsur rasa dan aroma. Kadar kafein pada kopi dipengaruhi oleh tempat tumbuh dan cara penyajian kopi. Mengkonsumsi kafein secara berlebih dapat mengakibatkan gejala pusing, gangguan tidur, dan meningkatkan sekresi gaster karena senyawa asam di dalam kafein (Lelyana R., 2008).

Di salah satu daerah di NTB, di lereng sebelah utara rinjani tepatnya di desa Sajang kecamatan sembalun terkenal dengan komuditas kopinya. Berada pada ketinggan yang cukup, kurang lebih 1000 MDPL, warga yang berjarak $93 \mathrm{KM}$ dari kota mataram ini memanfaatkan lahan untuk menanam kopi arabika. Berbeda dengan kopi robusta yang bisa bekembang dengan baik di dataran rendah kopi arabika memiliki tingkat keasaman yang lebih tinggi. Selain ketinggian lahan, kualitas kopi juga dipengaruhi oleh nutrisi dari alam dan cara pengolahan. Seiring dengan perkembangan zaman pengelolah kopi juga makin banyak jenisnya.

Pengelolaan kopi di desa sajang masih sangat organik, hal ini dapat dilihat dari cara perawatan pohon kopinya. Pohon kopi di desa sajang tidak menggunakan pestisida kimia melainkan menggunakan pupuk alami yakni daun-daun dari pohon-pohon yang jatuh di biarkan sebagai pupuk alami. Selain dari pengelolaan pohon kopinya, biji kopi yang sudah dipetik dikelola dengan berbagi teknik, ada yang semi wash dan full wash. Namun masih ada beberapa kendala yang dihadapi oleh produsen kopi sajang ini, diantaranya masalah pemasaran dan desain kemasan kopi kurang menarik.

Masalah pemasaran ini disebabkan karena lokasi tempat yang terlalu jauh, kurang dan sulitnya akses jalan menuju ke lokasi sehingga para konsumen kesulitan untuk mengetahui tentang kopi sajang dan produsen mengalami kesulitan untuk mendistribusikan produk mereka dikarenakan kurangnya sumber daya manusia dan akses jalan tersebut. Sehingga dibutuhkan sarana pemasaran yang efektif. Promosi atau pemasaran adalah upaya untuk memberitahukan atau menawarkan produk atau jasa pada dengan tujuan menarik calon konsumen untuk membeli atau mengkonsumsinya. Menurut john westwood pemasaran merupakan sebuah usaha terpadu yang dilakukan untuk memenuhi kebutuhan konsumen dan memberikan keuntungan/ laba kepada pengusaha.

Ada beberapa jenis pemasaran diantaranya word of mouth marketing (promosi dari mulut ke mulut), dimana calon konsumen mendapatkan informasi produk dari konsumen lain yang 
disampaikan secara oral. Call to Action (CTA), jenis ini memanfaatkan website yang memakai text, grafik, dan element web lainnya. Cloud Marketing, jenis ini memasukkan semua sumberdaya dan asetnya melalui online, salah satu contoh cloud marketing adalah affiliate program yang dilakukan oleh ama Menurut Shama kabani "online marketing adalah sebuah seni dan ilmu yang memanfaatkan internet untuk menyampaikan sebuah pesan sehingga kita dapat membuat orang lain untuk melakukan sebuah aktivitas, dimana contoh dari aktivitas tersebut adalah membeli produk atau jasa kita". Salah satu tujuan promosi menurut Rossiter dan percy (dalam Tjiptono,2002:222) memperkenalkan dan memberikan pemahaman tentang suatu produk kepeda konsumen (brand awareness).

Pembaharuan desain disebabkan desain kemasan awal yang kurang menarik, dimana desain awal terkesan simpel dan memiliki kekurangan seperti kurangnya logo produk dalam kemasan tersebut sebagai identitas produk. Kemasan (merek) merupakan salah satu bagian terpenting dari suatu produk. Merek dapat menjadi suatu nilai tambahan bagi produk baik itu produk berupa barang maupun jasa. Sedangkan menurut Kotler dan Keller merek merupakan nama istilah lambang atau desain atau kombinasinya yang dimaksukan untuk mengidentifikasi barang atau jasa dari salah satu penjual atau kelompok penjual dan mendiferensiasikan mereka dari pesaing. Dengan adanya promosi produsen atau distributor mengharapkan kenaikannya angka penjualan. Dari kekurangan kekurangan yang ada kami dari tim KKN tematik universitas Mataram melakukan pembaharuan desain kemasan kopi dan membantu pemasaran dengan membuat media sosial sebagai alat bantu pemasaran kopi tersebut.

Hasil yang daharapakan dari kegiatan ini adalah terwujud kemasan kopi yang lebih menarik dari sebelumnya dan lebih memudahkan dalam pemasaran melalui media sosial yang sudah dibuat.

\section{METODE PELAKSANAAN}

\section{Waktu dan Tempat}

Kegiatan dilakukan selama 2 minggu Dusun Sajang RT 03, Desa Sajang, Kecamatan Sembalun, Kabupaten Lombok Timur.

\section{Alat dan Bahan}

Alat yang digunakan dalam program ini adalah laptop,aplikasi editor ( Adobe Photoshop),gunting, silet, penggaris, printer, akun instagram, banner, dan meja. Sedangkan bahan yang digunakan adalah kertas stiker, wi-fi.

\section{Prosedur Kerja Branding dan Promosi Kopi Organik Khas Sajang}

Prosedur kerja Branding dilakukan dengan cara wawancara untuk mencari informasi tentang produk kopi organik sajang. Selanjutnya berdiskusi bersama pihak yang bersangkutan mengenai pembaharuan desain kemasan kopi. Kemudian merancang desain yang sudah disepakati bersama menggunakan aplikasi Adobe Photoshop.

Sedangkan prosedur kerja promosi dilakukan dengan cara membuat akun media sosial untuk produk kopi tersebut dan membuka bazar produk kopi organik sajang. 


\section{Bentuk Kegiatan}

Bentuk kegiatan secara keseluruhan ini adalah 1) persiapan program 2) desain produk 3) pembuatan akun media sosial 4) melakukan promosi secara langsung dan melalui akun media sosial.

\section{HASIL DAN PEMBAHASAN}

Program peningkatan kopi organik sajang melalui Branding dan Promosi di dusun Sajang dilakukan secara terstruktur dan melibatkan pihak yang bersangkutan.

\section{Pelaksanaan Program Peningkatan Kopi Organik Sajang}

Kegiatan program peningkatan kopi organik ini dimulai dengan persiapan program yang meliputi wawancara dengan pihak yang bersangkutan mengenai produk kopi organik tersebut. Hasil dari wawancara tersebut menunjukkan bahwa produk tersebut membutuhkan 1) Desain logo produk sebagai identitas produk kopi organik tersebut 2) Pembaharuan desain kemasan agar lebih menarik dan lengkap 3) website dan media sosial resmi dari kopi organik sajang sebagai media promosi tambahan.

Tahap selanjutnya yaitu mendiskusikan desain logo yang akan digunakan pada kemasan kopi organik sajang. Setelah mendapatkan kesepakatan untuk desain logo tersebut kemudian kami membuat desain logo dan kemasan dari produk kopi organik sajang mengggunakan aplikasi Adobe Photoshop. Aplikasi Adobe Photoshop adalah perangkat lunak editor citra buatan Adobe Systems yang dikhususkan untuk pengeditan foto/gambar dan pembuatan efek.

\section{Branding Produk Kopi Organik Sajang}

Kegiatan branding kopi organik sajang ini bertujuan untuk memperbaharui desain kemasan produk kopi organik sajang. Pembaharuan dilakukan dengan cara mengubah desain awal dan menambahkan logo dari desain kemasan yang kami buat. Logo merupakan suatu gambar atau sekedar sketsa dengan arti tertentu dan mewakili suatu arti dari perusahaan, daerah, organisasi, produk, negara, lembaga, dan hal lainnya membutuhkan sesuatu yang singkat dan mudah diingat sebagai pengganti dari nama sebenarnya. Sehingga pada produk kopi organik sajang membutuhkan logo sebagai identitas dari produk tersebut.

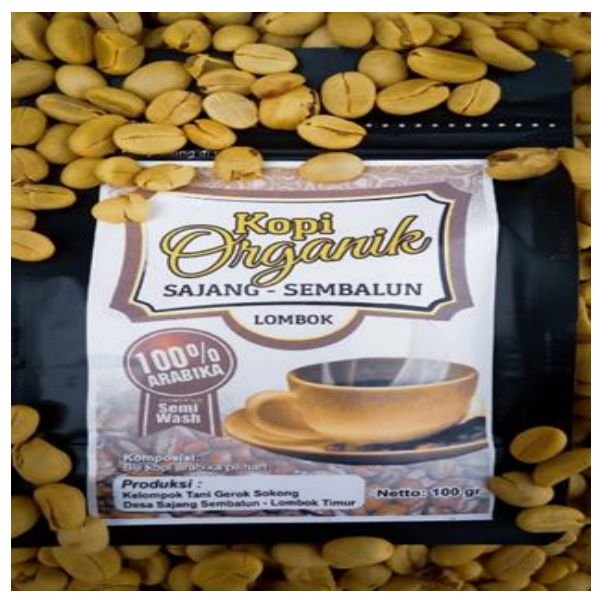

(a)

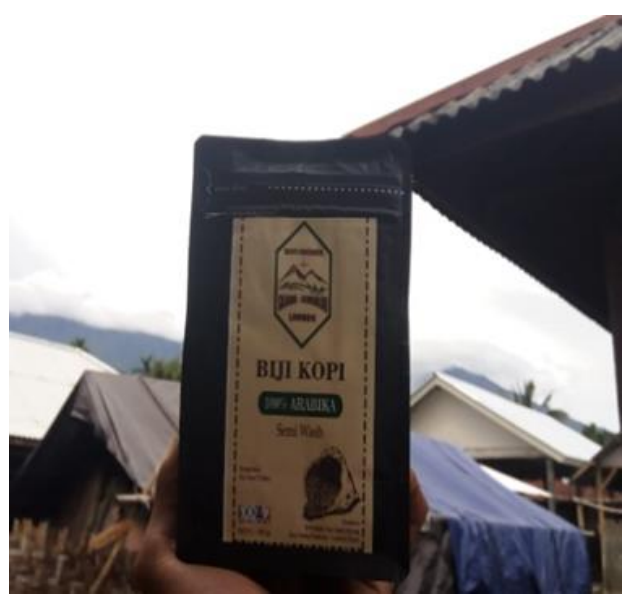

(b)

Gambar 1 (a) kemasan kopi organik sajang sebelum pembaharuan; (b) kemasan kopi organik sajang setelah pembaharuan. 


\section{Promosi Produk Kopi Organik Sajang}

Kegiatan promosi produk organik sajang ini dilakukan secara langsung dan tidak langsung (melalui media sosial). Kegiatan promosi ini bertujuan untuk mengenalkan kopi organik sajang secara luas kepada dunia. Sebelum melakukan promosi , kami terlebih dahulu membuat akun media sosial dan website sebagai media promosi produk kopi organik sajang. Untuk media sosial kami hanya membuat akun instagram, dengan nama @Kopiorganiksajang. Pembuatan akun media sosial Instagram dilakukan karena dimana saat ini akun Instagram menjadi media online yang popular sehingga sangat cocok menjadi media promosi online.
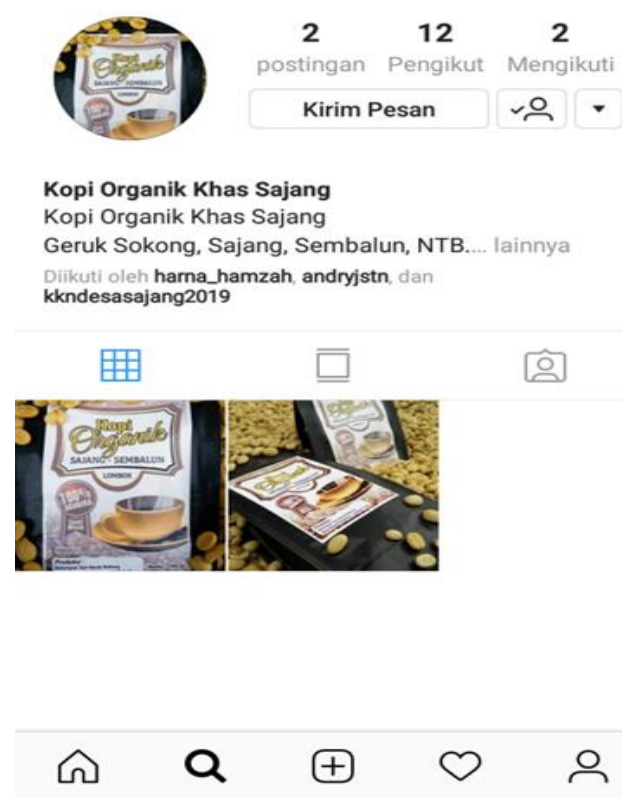

Gambar 2. Akun media sosial instagram kopi organik sajang

Untuk promosi secara langsung dilakukan dengan cara mulut ke mulut, promosi ke kerabat, teman, ke berbagai perkumpulan, komunitas, dan organisasi serta membuka stand bazar.

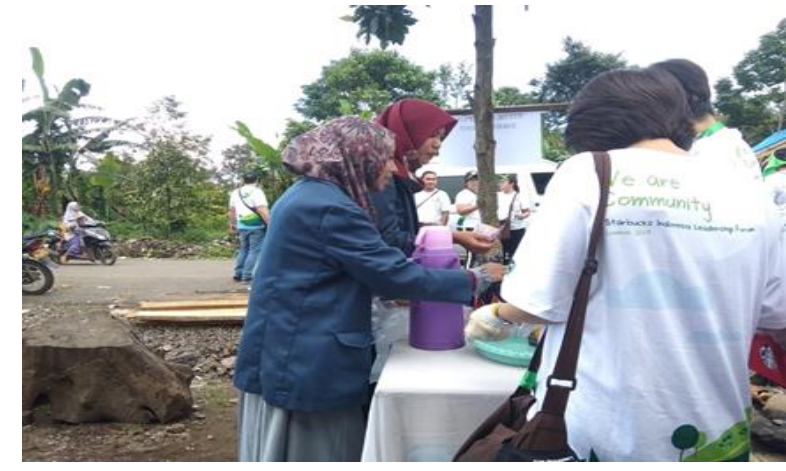

(a)

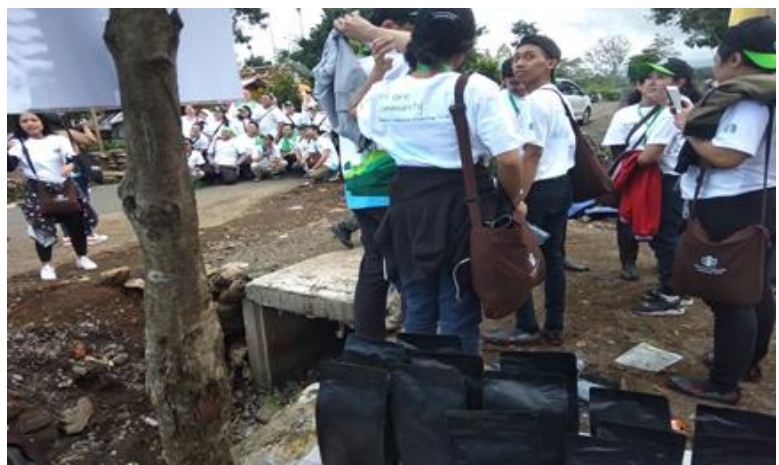

(b)

Gambar $3 \quad$ (a) kegiatan promosi dengan komunitas habitat; (b) komunitas Habitat

Melakukan promosi keberbagai perkumpulan seperti organisasi dan komunitas adalah sesuatu hal yang penting untuk dilakukan karena organisasi atau komunitas merupakan suatu kelompok sosial di masyarakat yang terdiri dari beberapa individu. Kegiatan promosi dengan membuka stand bazar dilakukan saat ada event - event tertentu. 


\section{KESIMPULAN}

Kesimpulan dari program peningkatan kopi organik sajang melalui branding dan promosi adalah dihasilkannya logo produk kopi organik sajang, dan desain kemasan yang lebih menarik dan lengkap. Adanya akun media sosial produk kopi organik sajang dan website sebagai media promosi. Saran untuk KKN selanjutnya agar lebih di kembangkan lagi baik dari segi promosi dan dari desain kemasan kopi sajang.

\section{REFERENSI}

Alma, Buchari. 2014. Manajemen Pemasaran dan Jasa. Bandung: Alfabet.

Bhara,M. 2005. Pengaruh Pemberian Kopi Dosis Bertingkat Per Oral 30 Hari Terhadap Gambaran Histopologi Hepertikus Wistar. Universitas Diponegoro: Semarang.

Kamus Besar Bahasa Indonesia, 2017.

Kotler, Philip. 2010. Manajemen pemasaran. Edisi tiga belas Bahasa Indonesia. Jilid 1 dan 2. Jakarta : Erlangga.

Kotler, Philip. 2004. Manajemen Pemasaran Analisis, Perencanaan dan Pengendalian. Jakarta : LPFE-UI.

Lelyana, R. 2008. Pengaruh Kopi terhadap Kadar Asam Urat Darah, Study Eksperimen pada tikus Rattus Norwegicus Galur Wistar. Universitas Diponegoro: Semarang.

Munaf, Triawan. 2017. Aroma Kopi Nusantara. Majalah Retas.

Palgunadi, Bram. 2007. Disain Produk 2 : Analisis dan Konsep Disain. Bandung : Penerbit ITB.

Ridwansyah. 2002. Pengolahan Kopi Edisi Ke-2. Medan: Usulibrary.

Saputra, E,. 2008. Kopi. Harmoni: Yogyakarta.

Tjiptono, Fandy. 2002. Strategi Pemasaran. Andi: Yogyakarta. 